\title{
Sobre o Autismo, Neuroinflamaçáo e Modelos Animais para o Estudo de Autismo: Uma Revisão
}

\author{
Autism, Neuroinflammation and Animal Models for the Study of Autism: A Review
}

Maria Martha Bernardi', Thiago Berti Kirsten ${ }^{2}$, Mácio Oliveira Trindade ${ }^{3}$

\section{RESUMO}

Este artigo busca mostrar a relevância de modelos animais no estudo da síndrome autista por meio de revisão da literatura. Embora eles possam ser discutidos pela sua limitação, a contribuição no entendimento da síndrome e possibilidades de procedimentos que não são possíveis em humanos por razóes éticas permite desvendar alguns aspectos dessa desordem. O autismo é um distúrbio psiquiátrico de desenvolvimento que se caracteriza por alteraçóes comportamentais desde a infância, tais como prejuízo na comunicação, na interação social, além de movimentos repetitivos e estereotipados e dificuldades de aprendizado. Esses sintomas podem ser severos ou moderados e/ou parciais, além de nenhuma manifestação ser exclusiva desse transtorno, o que dificulta o diagnóstico. Os achados neuroanatômico-funcionais são inespecíficos, assim como os estudos genéticos. Além da eventual predisposição genética, fatores ambientais, como a neuroinflamação, podem aumentar a incidência do autismo. A corrente de estudos atribuindo distúrbios mentais, inclusive o autismo, a alterações imunes se apóia cada vez mais em inúmeras publicaçóes recentes, envolvendo achados neuroimunes e desenvolvimento de diversos modelos animais. $\mathrm{O}$ presente trabalho realizou uma revisão sobre o autismo, discutindo a contribuição dos modelos animais para o estudo desta síndrome, além de discorrer sobre a participação da neuroinflamação como um fator associado à gênese desta patologia.

Unitermos. Autismo, Comportamento Animal, Transtornos do Desenvolvimento Infantil, Modelos Animais.

Citaçáo. Bernardi MM, Kirsten TB, Trindade MO. Sobre o Autismo, Neuroinflamaçáo e Modelos Animais para o Estudo de Autismo: Uma Revisão.

\begin{abstract}
This article aims to discuss and review the relevance of animal models to study the autistic syndrome. Whereas the animal models may be discussed by its limitation, the contribution to understand the autistic syndrome and the possible procedures, that are not possible in humans for ethical reasons, contributes to reveal some aspects of this disorder. Autism is a developmental neuropsychiatric disorder characterized by several behavioral changes, such as impaired communication and social interaction, repetitive and stereotyped activity and learning difficulties. These symptoms can be severe or moderate and/or partial, but no event is exclusive to autism disorder, which complicates the diagnosis. The neuroanatomical-functional findings and genetic studies are nonspecific. Besides this possible genetic predisposition, environmental factors, such as neuroinflammation, may induce autism. The current studies attributing the immune alterations to mental disorders, including autism relies increasingly on numerous recent publications involving neuroimmune findings and development of various animal models. This article constitutes a review of autism, discussing the animal models to study this syndrome, and the neuroinflammation contribuction in the pathogenesis of autism.
\end{abstract}

Keywords. Autism, Animal Behavior, Child Development Disorders, Animal Models.

Citation. Bernardi MM, Kirsten TB, Trindade MO. Autism, Neuroinflammation and Animal Models for the Study of Autism: A Review.

\footnotetext{
Trabalho realizado no Departamento de Patologia, Faculdade de Medicina Veterinária e Zootecnia, Universidade de Sáo Paulo, Sáo Paulo-SP, Brasil. 1.Neurocientista, Doutora, Professor adjunto da Faculdade de Pedagogia do Centro de Ciências e Humanidades, Universidade Presbiteriana Mackenzie, São Paulo, SP, Brasil, e pesquisadora do Departamento de Patologia, Faculdade de Medicina Veterinária e Zootecnia, Universidade de São Paulo, São PauloSP, Brasil.

2.Biólogo, Mestre, Doutorando do Programa de Pós-graduaçáo em Patologia Experimental e Comparada do Departamento de Patologia, Faculdade de Medicina Veterinária e Zootecnia, Universidade de São Paulo, São Paulo-SP, Brasil.

3.Bacharel em Educação, Mestrando do Programa de Educação, Arte e História da Cultura da Universidade Presbiteriana Mackenzie, Professor Assistente do Centro de Ciências e Humanidades da Universidade Presbiteriana Mackenzie, São Paulo-SP, Brasil.
}

Endereço para correspondência: Maria Martha Bernardi Departamento de Patologia, Faculdade de Medicina Veterinária e Zootecnia, Universidade de São Paulo, SP R. Prof. Orlando Marques de Paiva, 87 Tel/ Fax.: +551130911376/ +55113091 7829, CEP 05508-000, São Paulo-SP, Brasil. E-mail: marthabernardi@gmail.com 


\section{INTRODUÇÃO}

O presente trabalho realizou uma revisão sobre o autismo, discutindo a contribuição dos modelos animais para o estudo desta síndrome, além de discorrer sobre a participação da neuroinflamação como um fator associado a gênese desta patologia.

Os distúrbios do desenvolvimento são um problema de longa data, que afetam famílias e a integração de crianças na sociedade. Nesse sentido, desde o século passado, existe a concepção de que as relaçôes interpessoais seriam os principais determinantes da natureza humana, havendo desde essa época várias reflexóes sobre o assunto ${ }^{1}$.

O presente trabalho tem como propósito a revisão das principais teorias propostas para explicar as causas da síndrome autista, seu diagnóstico, alterações no sistema nervoso central (SNC) e genéticas, as teorias neuroimunes, bem como os modelos experimentais para o estudo da síndrome, com o objetivo de contribuir para o seu entendimento.

\section{Teorias da síndrome autística}

Os Transtornos Invasivos do Desenvolvimento caracterizam-se por prejuízo severo e invasivo em diversas áreas do desenvolvimento: habilidades de interação social recíproca, habilidades de comunicação, ou presença de comportamento, interesses e atividades estereotipados. Os prejuízos qualitativos que definem essas condiçôes representam um desvio acentuado em relação ao nível de desenvolvimento ou idade mental do indivíduo. Estes transtornos incluem o Transtorno Autista, Transtorno de Rett, Transtorno Desintegrativo da Infância, Transtorno de Asperger e Transtorno Invasivo do Desenvolvimento Sem Outra Especificação (DSM IV)2.

O transtorno autista é um distúrbio psiquiátrico de desenvolvimento que se caracteriza por atraso ou total ausência da comunicação verbal (atraso ou ausência de linguagem, linguagem estereotipada ou idiossincrática, incapacidade de iniciar ou sustentar uma conversa). Essas dificuldades podem ser graves, presentes na interação social (ausência de reciprocidade afetiva e pobreza de comportamentos e formas de comunicação não verbais como linguagem gestual, contato visual, expressão facial, etc), padróes de comportamento e interesses restritos (maneirismos, movimentos repetitivos ou estereotipados, preocupação excessiva com partes ou características não funcionais de objetos ou rotinas, preocupação excessiva e exclusiva por um tema restrito, etc) e ainda pobreza do pensamento abstrato de tipo simbólico e imaginativo. Quase sempre existem importantes dificuldades de aprendizagem e baixo QI. Convêm ressaltar que, em algumas crianças autistas, esses sinais e sintomas são severos ou moderados e instáveis, há também aquelas que manifestam apenas alguns deles. Essa ampla variedade de comportamentos expressas nos autistas é o motivo pelo qual tal transtorno é amplamente referido como transtorno do espectro autista (DSM IV - F84.0 - 299.00 e CID 10 F84.0 $)^{2-7}$.

Devido à diversidade no quadro clínico do autismo, associada ao fato de que nenhum dos aspectos supracitados por si só é exclusivo desse transtorno, seu diagnóstico é eminentemente clínico, sendo composto de várias características, descritas no DSM IV (F84.0 - 299.00)2 Nesse sentido, ainda não existem exames complementares que possam validar o diagnóstico clínico ${ }^{4}$.

A detecção da doença pode ocorrer geralmente antes dos três anos de idade, sendo alguns sintomas perceptíveis já aos seis meses de idade ${ }^{8}$, com prevalência de aproximadamente um autista em 150 crianças nascidas ${ }^{9}$. A proporção de autismo entre os sexos masculino e feminino é de $4: 1^{10}$, havendo, no entanto, evidências que, em meninas, a síndrome possa se expressar de forma mais severa ${ }^{11}$.

O termo autismo foi utilizado pela primeira vez por Bleuler em 1911, para denominar pacientes com perda do contato com a realidade, dificultando ou mesmo impossibilitando a sua comunicação ${ }^{12}$. A primeira descrição da síndrome foi feita por Leo Kanner, em 1943, por meio de análises clínicas feitas por ele em onze crianças, todas elas apresentando os mesmos sintomas já mencionados ${ }^{13}$.

Algumas teorias tentam explicar as causas do autismo. A teoria psicanalítica apresenta diversas subteorias na tentativa de explicar os fatores causadores e o funcionamento do autismo no aparelho psíquico das crianças. Um dos fatores apontados por ela é que o autismo teria ligação com a depressão materna. Sendo assim, a depressão interferiria com a capacidade materna de envolver-se emocionalmente e cuidar sadiamente da criança, ainda muito pequena, e essa deficiente relação mãe-bebê é que eliciaria o transtorno ${ }^{13,14}$. 
O autismo resultaria da ativação excessiva das primitivas defesas do ego (mediador entre sensações internas e externas) em termos de inibição do desenvolvimento, havendo conflitos constantes e intensos entre o instinto de vida e de morte ${ }^{15,16}$. Essa situação promoveria altos níveis de ansiedade levando a uma postura esquizoparanóide-simile.

Baseada em aspectos evolutivos (teoria evolutiva), o autismo é um subgrupo das psicoses infantis e uma regressão ou uma fixação a uma das fases de desenvolvimento infantil ${ }^{17}$. Neste caso, a criança não diferenciaria sensações ou estímulos internos e externos. Assim, a criança não perceberia, de igual maneira, a própria mãe como representante do ambiente externo. A autora supóe que existe um período denominado por ela de "autismo normal" em que pode ou não ocorrer à fixação do distúrbio. Haveria uma predisposição ao autismo desde o nascimento em todas as crianças, e, diante destas condiçóes, a experiência para o bebê de separação materna se tornaria intensamente traumática, levando-o à total desorganização de sensações seguida de depressão. Esse seria o ponto no qual a criança se fixaria ${ }^{18}$.

Outra linha teórica denominada afetiva propóe que a criança autista teria inabilidade inata de se relacionar emocionalmente com outras pessoas e, ainda, que ela se originaria de uma disfunção do sistema afetivo ${ }^{19}$. Este fato impediria que o autista tivesse capacidade de abstrair e simbolizar. Por esta razão a criança não teria a linguagem bem desenvolvida, relacionamento afetivo, abstração e simbologia, pois não captaria os estímulos corporais verbais e muito menos os não verbais.

$\mathrm{Na}$ "teoria da mente", é proposto que os autistas teriam dificuldades em compreender estados mentais de outros, como por exemplo, desejos, chamados de metarepresentações. Assim, a mente de um autista não estaria apta ao convívio social compreensível e compatível com os demais, e tampouco seria organizado de maneira a ordenar percepçóes internas ${ }^{20}$. Muitas crianças autistas conseguiriam perceber algumas categorias específicas de reconhecimento, embora não consigam identificar adequadamente os estados mentais mais sutis ${ }^{21}$. Esses autores estudaram o reconhecimento facial por meio da apresentação de quatro figuras (alegria, tristeza, raiva e surpresa) a 30 adultos considerados normais, 51 crianças conside- radas normais e a 30 crianças diagnosticadas como autistas. Comparados os níveis de acertos entre os três grupos, verificaram-se diferenças significativas entre as respostas das crianças autistas e os demais grupos, com menor reconhecimento facial dos autistas. Os autores atribuem essas diferenças a incapacidade da criança autista de atribuir um significado específico a expressão facial, embora reconheça os elementos que formam determinada expressão. Essa dificuldade da percepção das expressôes faciais interferiria diretamente nos relacionamentos sociais.

Nas teorias neuropsicológicas e de processamento da informação haveria uma deficiência cognitiva no autismo $^{22}$. Crianças autistas mostrariam deficiências cognitivas específicas, tais como: 1) problemas na percepção de ordem e significado, as quais não poderiam ser explicadas por deficiência mental; 2) dificuldades em usar input sensorial interno para fazer discriminações na ausência de feedback de respostas motoras e 3) tendência a armazenar a informação visual, utilizando um código visual, enquanto as crianças com desenvolvimento normal usavam códigos verbais e/ou auditivos ${ }^{23}$.

\section{Diagnóstico do autismo}

Um fato importante a se lembrar no autismo é que não se está diante de um único autismo, mas sim de uma gama de formas psicopatológicas, que vai do autismo profundo até a chamada síndrome de Asperger, considerado por alguns autores como um autismo brando ${ }^{24}$. Assim, o grupo de distúrbios autismo-simile é denominado como distúrbio de espectro autista.

Para diagnosticar o autismo, são utilizados critérios descritos no Manual de Diagnóstico e Estatístico da Associação Americana de Psiquiatria (DSM), que evoluiu com o passar dos anos, separando o autismo da esquizofrenia, obtendo nova forma de diagnóstico: autismo ou transtorno autista (DSM IV - F84.0 - 299.00)². No diagnóstico de autismo, existem graus para diferenciação de subgrupos de indivíduos com finalidades práticas e de pesquisa. A principal intenção dos critérios para diagnosticar o autismo e os distúrbios relacionados é reduzir as divergências entre pesquisadores e clínicos em um nível comportamental e biológico. Os critérios para o diagnóstico clínico do autismo também foram estabelecidos pela Classificação Internacional de Doenças (CID 10 F84.0) ${ }^{7}$. 
O diagnóstico de autismo requer análise cuidadosa nas avaliaçóes de linguagem e neuropsicológica e exames complementares (como estudos de cromossomos, e neuroimagem). Somente dessa forma, a compreensão da patofisiologia dos distúrbios será possível. As avaliaçóes mais utilizadas para o diagnóstico de autismo são o Sistema Diagnóstico de Observação do Autismo (ADOS) e a Entrevista Diagnóstica de Autismo (ADI), representando, ambas, uma entrevista estruturada bastante completa e um método de observação para avaliar objetivamente as habilidades sociais, de comunicação e de comportamento de indivíduos em todos os graus do autismo. Mais ainda, estão disponíveis instrumentos validados para população brasileira como a CARS (Childhood Autism Rating Scale, ou Escala de avaliação para autismo infantil) e ABC (Autism Behavior Checklist ou Lista de checagem de comportamento autístico), que auxiliam na identificação de características autísticas, sendo instrumentos multidisciplinares ${ }^{25,26}$.

\section{Possíveis alteraçóes no sistema nervoso dos autistas}

Extensas investigaçóes revelaram o envolvimento de várias regiôes cerebrais na gênese do autismo, incluindo o sistema límbico, amígdala, áreas pré-frontais e cerebelo $^{3}$. As aberraçóes poderiam ser induzidas em múltiplos períodos pré-natais, especialmente nas regióes cerebrais que se desenvolvem tardiamente na neurogênese. Além disso, nesse caso, regiôes cerebrais envolvidas com o autismo tendem a se desenvolver mais lentamente e são mais vulneráveis a distúrbios ${ }^{27}$.

A respeito desses distúrbios, estudos de autópsia em pacientes diagnosticados com autismo mostraram atrofia do córtex do neo-cerebelo, com perda acentuada de células de Purkinje ${ }^{28}$. Métodos de neuroimagem também demonstram alteração estrutural do cerebelo ${ }^{29,30}$. Estudos funcionais mostraram ainda alteração dos padróes de ativação do cerebelo desses pacientes, com hipoativação em tarefas de atenção não motora ${ }^{31}$.

Os estudos de neuroimagem sugerem ainda um padrão anormal de desenvolvimento cerebral em autistas, com um crescimento acelerado durante os primeiros anos de vida, seguido por uma desaceleração em algumas regióes do cérebro, enquanto em outras áreas há uma parada do crescimento ${ }^{32}$.
O tamanho da cabeça de autistas tende a ser semelhante ao de crianças típicas ao nascer, no entanto, entre dois e quatro anos de idade, $90 \%$ dos autistas têm volume cerebral maior do que a média para crianças da mesma idade, e $37 \%$ apresentam macrocefalia ${ }^{32}$.

Foram noticiadas alteraçóes neuroanatômicofuncionais em crianças autistas, detectadas por meio da ressonância nuclear magnética e da tomografia computadorizada por emissão de fóton único ${ }^{4}$. As alteraçôes anatômicas estavam preferencialmente localizadas no corpo caloso, além do septo pelúcido, dos ventrículos cerebrais, do cerebelo, lobo temporal, lobo occipital e hipocampo. As alteraçôes funcionais predominaram no lobo frontal, lobo temporal, lobo parietal e nos núcleos da base.

Outro dado interessante é que pacientes autistas podem apresentar distúrbios na substância branca e desconexão entre regióes cerebrais ${ }^{33}$.

Com relação aos níveis de neurotransmissores nestes pacientes, embora com dados algumas vezes bastante contraditórios, a alteração neuroquímica mais prevalente seria da elevação nos níveis de serotonina nas plaquetas. Além disso, observa-se eventual aumento na captação de serotonina e diminuição da ligação a receptores 5-HT25 $5^{32}$.

Outros estudos apontam para alteraçóes dopaminérgicas associadas ao autismo, ligadas a processos emocionais $^{34}$. Por exemplo, benefícios clínicos obtidos graças a um agonista do receptor dopaminérgico D2 suportam o conceito de desregulação do sistema dopaminérgico central nesses pacientes.

Além da serotonina e dopamina, alguns trabalhos tentam associar o autismo com a adrenalina, noradrenalina, ocitocina, vasopressina, glutamato e ácido gamaaminobutírico ${ }^{27}$.

Pode-se concluir que, da mesma forma que o autismo se manifesta com diferentes graus de intensidade e manifestaçóes comportamentais, diversos quadros neurológicos são relacionados ao autismo, incluindo interessantes achados neuroanatômico-funcionais, porém, com natureza inespecífica e variada. Dessa forma, até agora, nenhuma resposta definitiva foi encontrada quanto ao autismo e alteraçóes no SNC.

\section{Possíveis alteraçóes genéticas nos autistas}

A probabilidade de recorrência de autismo em 
uma família que já possui uma criança autista é considerada elevada (de 3 a 8\%). Em gêmeos monozigóticos, em até $92 \%$ dos casos é diagnosticado algum espectro de autismo nas duas crianças ${ }^{32}$. Nos gêmeos dizigóticos o diagnóstico ocorre em até $24 \%$ dos $\operatorname{casos}^{27}$.

Estudos indicam que cerca de 20 genes podem estar envolvidos no autismo ${ }^{35,36}$. Por exemplo, análises de ligação estudando todo o genoma encontraram sinais positivos de correlação nos cromossomas 2, 7, 1 e 17, particularmente em 2q e 7q. Genes como FOXP2, RELN e HOXA1 parecem estar associados, embora com achados ainda inconsistentes ${ }^{32}$. Outro estudo revela uma relação entre autismo e a transmissão preferencial de alelos de marcadores genéticos de dois genes transportadores de serotonina ${ }^{37}$. Porém, esses achados não foram replicados em um estudo posterior ${ }^{32}$.

A síndrome autística é clinicamente heterogênea e pode ser associada em mais de $10 \%$ dos casos com outras desordens neurológicas e genéticas, como a esclerose tuberosa, X frágil, síndromes de Rett e Down ${ }^{38-40}$.

Embora múltiplos cromossomas e genes tenham sido implicados com o autismo, não se chegou a nenhuma conclusão definitiva, uma vez que muitos desses achados são contraditórios, provavelmente graças à grande heterogeneidade das manifestaçôes autistas.

\section{A neuroinflamação na patogênese do autismo}

Diversas linhas de pesquisa demonstram que tanto fatores genéticos como ambientais influenciariam o desenvolvimento de anormalidades na circuitaria neural que desencadeia o autismo. Recentemente, muitos trabalhos focam nas conexóes entre o sistema imune e sistema nervoso. Existem achados de anormalidades imunes periféricas e, mais recentemente, ativaçáo de neuroglia, do sistema imune no cérebro e no fluído cerebroespinhal de pacientes com autismo ${ }^{33}$.

Todos os tipos celulares neurais e não neurais que fazem parte do SNC em desenvolvimento, como micróglia e células endoteliais, usam citocinas para sinalizaçóes parácrinas e autócrinas, e, pelo fato de muitas dessas mesmas citocinas também servirem como moduladores imunes, processos de desenvolvimento normais mediados por citocinas podem ser susceptíveis a distúrbios por desregulação imune, como por exemplo, a partir de infecçóes maternas ${ }^{41}$.
A alta prevalência de autistas (1 para cada 150 pessoas) pode ter contribuiçóes de fatores ambientais. Algumas variaçôes genéticas conferem vulnerabilidade a estressores ambientais. Essa influência ambiental inclui alteraçôes patofisiológicas do SNC, incluindo estresse oxidativo, neuroinflamação, disfunção mitocondrial (por exemplo, poluição do ar, metais pesados) e distúrbios bioquímicos. Fatores da dieta e contaminantes alimentares também podem contribuir para este risco. A influência ambiental na fisiologia poderia se iniciar in utero, e, em consequência, contribuir para alterações no cérebro e em outros sistemas corporais em desenvolvimento, havendo a possibilidade de envolver mudanças epigenéticas ${ }^{42}$. Assim injúrias pré- ou perinatais, toxicidade ao mercúrio, ou infecçóes virais persistentes seriam interferências ambientais que aumentariam o risco de autismo com relação aos fatores genéticos por si só ${ }^{43,44}$.

Foram relatados alguns casos de evidências patológicas de reaçóes imunológicas, especialmente da resposta imune inata no SNC, como infiltração linfocitária e nódulos microgliais ${ }^{45,46}$. Crianças autistas podem apresentar anormalidades tanto nas funçôes imunes humoral como celular, como por exemplo, diminuição da produção de imunoglobulinas ou disfunçáo de células $\mathrm{B}, \mathrm{T}$ e $\mathrm{NK}^{47}$.

Além disso, o deslocamento do subconjunto de linfócitos $\mathrm{T}$ helper 1 para 2 e a associação com antígeno de leucócito humano sugerem a possibilidade de autoimunidade contra antígenos cerebrais, contribuindo para a neuropatologia do autismo ${ }^{48}$. Diminuição de subconjuntos de imunoglobulinas e complemento e ações de anticorpos maternos também são propostos como fatores patogênicos ${ }^{49}$.

É importante ressaltar que esses achados imunes não se repetem em muitos dos pacientes, inclusive quando se altera a idade do paciente e o momento da coleta. Desse modo não está claro se as alteraçôes refletiriam uma disfunção imune ou poderiam representar uma regressão que variam com a idade ${ }^{50}$.

Anticorpos agindo diretamente contra estruturas do SNC como no córtex frontal e células endoteliais cerebrais é um fenômeno descrito em pacientes autistas. A relação do autismo com a auto-imunidade é sugerida pela maior prevalência de desordens auto-imunes, como artrite reumatóide e lúpus em famílias com membros autistas ${ }^{33}$. 
Outro fator imune proposto como causa de autismo foi a vacinação das crianças contra o sarampo, caxumba e rubéola. Porém, esta corrente parece cada vez mais perder força, uma vez que não existem fatos comprovados. Além disso, o autismo vem sendo associado à intercorrências durante o desenvolvimento do feto, com alteraçóes no crescimento e desenvolvimento neuronal e não na infância (período da vacinação infantil) ${ }^{51}$. Eventos imune-mediados como as infecçôes maternas durante a gestação são importantes como potenciais indutores de alteraçôes em longo prazo na estrutura e função do cérebro em desenvolvimento.

Dessa forma, infecçóes virais pré-natais, incluindo rubéola e citomagalovírus, poderiam danificar o sistema imune imaturo, com produção elevada de citocinas próinflamatórias ${ }^{52-59}$. O mecanismo pelo qual a infecção viral desencadearia o autismo ainda é incerto, mas é proposto que seria pela (1) infecção direta no SNC, (2) por meio de infecção em outro local do corpo, agindo como gatilho para doença no SNC, (3) por meio de alteraçóes da resposta imune da mãe ou prole, (4) ou pela combinação desses fatores 5 . Isso deve ocorrer, pois o SNC não está totalmente desenvolvido ao nascimento ${ }^{60} \mathrm{e}$ é mais suscetível a danos virais ${ }^{61}$.

É importante ressaltar que grávidas são consideradas de certo modo como imunossuprimidas, e, portanto, mais suscetíveis a infecçóes ${ }^{62,63}$. Além disso, as citocinas poderiam ser diretamente produzidas no cérebro fetal, ou acessar o SNC atravessando a barreira hematoencefálica imatura. Essas citocinas podem alterar o desenvolvimento do cérebro ${ }^{64}$.

Um grupo de pacientes autistas mostrou aumento dos níveis de fator de necrose tumoral $\alpha$ no soro e líquido cerebroespinhal, reforçando a associação entre as citocinas e o autismo ${ }^{65}$. Além disso, são encontrados mais monócitos circulantes nesses pacientes ${ }^{66}$. Em outro estudo, níveis elevados de citocinas antiinflamatórias e próinflamatórias foram encontrados em alguns pacientes autistas em algumas regiôes cerebrais. Especialmente, as citocinas próinflamatórias resultariam em ativação microglial e neuroinflamação, associadas ao autismo. Já a elevação das citocinas antiinflamatórias teria papel de reparo do tecido injuriado ${ }^{33}$.

Em outro estudo, foi constatado que citocinas apresentam-se altamente elevadas em diversas regióes cerebrais e no líquido cefalorraquidiano de autistas entre 4 e 45 anos de idade ${ }^{41}$. Porém, segundo esses mesmos autores, ainda é preciso determinar se um desequilíbrio de uma citocina embrionária desencadeia tais desregulaçôes imunes no cérebro adulto, como esse estado imune alterado é estabelecido, e se intervenções no intuito de frear essa resposta imune seria terapeuticamente benéfica.

Existem evidências da ativação neuroglial na neuropatologia do autismo. Cérebros post-mortem de pacientes autistas apresentam processos neuroinflamatórios ativos no córtex cerebral, substância branca e cerebelo, incluindo achados nas técnicas imuno-histoquímicas e Western blot ${ }^{67}$. É possível que a ativação microglial presente no cérebro de autistas possa refletir no desenvolvimento anormal das vias fetais em resposta a fatores genéticos ou ambientais, como insultos intra-uterinos ${ }^{33}$.

Pacientes autistas podem também apresentar maior atividade do eixo hipotálamo-pituitária-adrenal, uma vez que foi encontrada maior concentração de cortisol na saliva de crianças autistas ${ }^{68}$ e níveis elevados de hormônio adrenocorticotrópico nos adultos com Asperger ${ }^{69}$.

Encarar processos infecciosos pré-natais como indutores do autismo é importante, pois pode ajudar a entender o motivo da alta prevalência do tal distúrbio, já que qualquer indivíduo está constantemente exposto a infecçôes ao longo da vida, especialmente as gestantes, que são consideradas imunossuprimidas ${ }^{62,63}$. Reforça ainda a importância do acompanhamento e pronto tratamento de gestantes, caso sejam infectadas. Por fim, esses estudos ajudariam a entender o mecanismo de ação do distúrbio, de modo a aprimorar tratamento a um indivíduo autista, ou, quem sabe, um dia chegar à "cura”. No entanto, vale ressaltar que a causa do autismo, até agora é desconhecida e há vários indícios de ser multigênica e multifatorial.

\section{Modelos experimentais de autismo}

Diversos estudos utilizam modelos animais para melhor entender as causas e consequências do autismo. Esses estudos levam em conta os achados comportamentais, neurais, imunes e genéticos encontrados nos autistas (humanos).

Os modelos animais de infecções pré-natais propóem mimetizar tanto infecçóes bacterianas quanto virais 
durante a gestação, principalmente com a administração de lipopolissacarídeo (LPS), vírus influenza e ácido poliinosinico-policitidilico (PolyI:C), injetadas pelas vias intraperitoneal, intravenosa, subcutânea e intranasal em roedores. O número de administrações durante a gestação, o período da gestação e a dose desses agentes infecciosos devem sempre ser levados em conta, pois podem resultar em alterações bastante heterogêneas entre os animais ${ }^{70}$.

Modelos animais de autismo utilizando infecçóes pré-natais apontam para a importância da ativação imune maternal no cérebro fetal em desenvolvimento ${ }^{71}$. A ativação imune maternal no meio da gestação de camundongos com PolyI:C (um análogo sintético de RNA viral) ou interleucina-10 resulta em prole com comportamentos, histologia e expressão gênica anormal, de modo similar ao de pacientes autistas ou esquizofrênicos ${ }^{72,73}$. Esses animais apresentam prejuízo sensório-motor, déficits no teste de inibição pré-pulso e na inibição latente, bem como na redução do número de receptores D1 (dopamina) préfrontal quando adultos.

No comportamento animal, hiperatividade, reatividade aumentada e estereotipada são comumente consideradas como sinais de autismo, apesar da falta de especificidade e sinais similares a esquizofrenia ${ }^{73,74}$. Entre os trabalhos relacionados a comportamentos repetitivos, estereotipados, restrição de interesse e resistência a mudanças, pode-se destacar um estudo que investigou a tarefa exploratória na prancha com furos (hole-board) em camundongos em meio a pistas olfativas ${ }^{75}$. Neste caso, camundongos com expressão reduzida do Grin1, que leva a hipofunção do receptor NMDA, apresentaram comportamentos repetitivos, sofrendo menor interferência de pistas olfativas, comparados a animais selvagens. Esses achados apontam para resistência a mudanças e interesses restritos.

Além dessa estereotipia, o autismo também é caracterizado pela alteração nas habilidades de comunicação social, sendo que limitaçóes nessa área só podem ser superadas pelo aumento da sofisticação da análise comportamental em situações sociais.

Nesse sentido, a observação do comportamento de brincar em roedores tem se mostrado importante ferramenta comportamental para o estudo do autismo. Comportamentos autistas foram observados experimentalmente em um modelo com ratos por meio da indução de doença do vírus Borna neonatal ${ }^{16}$. Nesse experimento, os animais apresentaram diminuição do comportamento de brincar, relacionados a achados de lesôes cerebelares. É importante lembrar que roedores nascem mais imaturos que seres humanos, por isso da escolha do tratamento no período neonatal.

Hornig et al. ${ }^{77}$ também fizeram paralelo do autismo com ratos inoculados intracerebralmente com vírus Borna, pouco depois do nascimento. Esses ratos apresentaram comportamentos estereotipados, atividade exploratória desregulada, atraso de crescimento, reflexos de endireitamento aberrantes, respostas motoras assimétricas, apoptose neural predominantemente no hipocampo e cerebelo, e elevação de transcrição de mRNA de interleucina- $1 \alpha,-1 \beta$ e -6 e de fator de necrose tumoral em distintas regióes de ratos infectados. Além disso, sabese que a resposta imune maternal a uma infecção pode influenciar o desenvolvimento do feto via aumento nos níveis de citocinas circulantes ${ }^{59,71}$.

Apesar dos estudos com sangue de crianças autistas não apontarem para evidências de infecção por vírus Borna, esses modelos animais revelam evidências que infecçóes virais e da consequente resposta imune podem desregular o desenvolvimento neural e promover anormalidades comportamentais, com similaridades ao autismo 5 .

Modelos animais envolvendo a administração via respiratória do vírus influenza em camundongos no meio da gestação também apresentam algumas anormalidades neuropatológicas e comportamentais similares na prole consistentes com o autismo, como deficiência na inibição pré-pulso, na resposta a alarme sonoro e na interação social $^{78}$. Vale lembrar, que o vírus influenza acomete mais humanos nas estações frias, especialmente no inverno, e, são justamente nesses períodos frios que são registrados as maiores incidências de crianças nascidas com certas desordens neuropsiquiátricas como a esquizofrenia ${ }^{73}$. Este fato reforça mais uma vez a relação da infecção materna durante a gestação e o autismo.

Além de infecções virais pré-natais, infecções prénatais bacterianas, que igualmente podem interferir no ambiente intra-uterino, inclusive com a produção de citocinas pró-inflamatórias, tem se mostrado como possíveis indutoras do autismo. O tratamento com LPS, um componente da parede celular de bactérias gram-negativas, 
que mimetiza a infecção bacteriana, no meio da gestação de ratas, leva a redução do comportamento de brincar nos filhotes e da interação social quando adultos ${ }^{79}$.

Assim como estudos científicos em humanos geralmente buscam avaliar a percepção do autista por pistas visuais, nos roedores, pode-se focar no sistema olfatório, que é o principal sistema sensorial deles, com funçóes de reconhecimento ambiental. Em um estudo conduzido em nosso laboratório, o reconhecimento materno por meio de pistas olfatórias foi empregado para investigar os primeiros sinais de relacionamento social filhote-mãe. Filhotes de ratos tratados ou não pré-natalmente com LPS no meio da gestação, foram avaliados quanto ao reconhecimento da maravalha materna por meio da olfação. Os roedores normalmente se encaminham para a maravalha com odor materno, mas a prole tratada com a endotoxina não se encaminhou para a maravalha materna ${ }^{80}$.

Finalmente, modelos experimentais utilizando medicamentos são propostos como modelos animais de autismo. Assim, a administração do ácido valpróico no meio da gestação de ratos, antes do fechamento do tubo neural resulta em anormalidades similares ao autismo ${ }^{81}$. Esses animais apresentam menor número de células de Purkinje no vermis cerebelar e reduçáo dos hemisférios. Tal exposição poderia ser resultado da administração de medicação anticonvulsivante em mães gestantes.

Com os diversos achados de diferentes modelos animais em diferentes laboratórios, pode-se claramente demonstrar que a ativação imune pré-natal pode causar alteraçôes nas funções do SNC da prole. Ainda se faz necessário aprofundar a caracterização dos fatores ambientais responsáveis por essas alterações cerebrais, bem como investir em estudos com primatas, já que essas desordens neurocomportamentais como o autismo têm forte componentes genéticos. Dessa forma, a extrapolação para humanos será cada vez mais precisa ${ }^{70}$.

O mecanismo de ação exato de como a ativação imune pré-natal resultaria em alterações em longo prazo no SNC relacionadas ao autismo ainda é impreciso, porém diversas evidências de mediadores imunes como citocinas circulantes, elevação dos níveis de citocinas na placenta, e estresse oxidativo no cérebro fetal ajudam a entender tal fenômeno ${ }^{70}$.

\section{CONCLUSÃO}

O autismo é um distúrbio psiquiátrico de desenvolvimento importante, ocupando o terceiro lugar entre os distúrbios do desenvolvimento, na frente das malformaçôes congênitas e da síndrome de Down ${ }^{32}$. Apesar de décadas de pesquisa, muito pouco se sabe sobre a etiologia e/ou patofisiologia do autismo. Esta parece ser resultado de uma complexa combinação de fatores ambientais, neurológicos, imunológicos e genéticos. Seu diagnóstico é difícil principalmente pela ausência de sintomas exclusivos do distúrbio e pela diferença na manifestação, quanto à severidade e variedade de sinais. $\mathrm{O}$ diagnóstico é eminentemente clínico, sendo que os diferentes achados neuroanatômico-funcionais e genéticos pouco contribuem para esse diagnóstico.

Os modelos animais já demonstraram claramente que a ativação imune pré-natal pode causar alteraçóes na função do SNC da prole, utilizando para tanto modelos principalmente em roedores. Isto sugere que a associação entre a infecção pré-natal e doenças do SNC em humanos pode, de fato, refletir uma relação causal. Assim é necessária a caracterização criteriosa do grau de modificação do SNC devido à ativação imunológica pré-natal em modelos animais. Experimentos para verificar o mecanismo responsável por essas mudanças incluindo investigaçóes sobre os mediadores da ativação aguda do sistema imune, bem como dos responsáveis pelas alteraçóes em longo prazo do SNC são imprescindíveis. Além disto, pode-se pensar em estender para outras espécies mais próximas do homem a investigação das consequências da inflamação materna pré-natal na sua prole. Para tanto, modelos animais que levam em consideração essa hipótese deverão ser cada vez mais sofisticados e podem se revelar uma eficiente ferramenta para ajudar a entender o autismo e ter importantes implicações clínicas e terapêuticas.

\section{REFERÊNCIAS}

1.Camargo SPH, Bosa CA. Competência social, inclusão escolar e autismo. Psicol Soc 2009;21:65-74.

2.Manual de diagnóstico e estatística de transtornos mentais (DSM IV) [endereço na Internet]. Porto Alegre: Artes Médicas. (atualizado em: agosto/2011; citado em: agosto/2011). Disponível em: http://virtualpsy.locaweb.com.br/dsm.php. 
3.Bugalho P, Correa B, Viana-Baptista M. Role of the cerebellum in cognitive and behavioural control: scientific basis and investigation models. Acta Med Port 2006;19:257-67.

4.Machado MG, Oliveira HA, Cipolotti R, Santos CA, de Oliveira EF, Donald RM, et al. Anatomical and functional abnormalities of central nervous system in autistic disorder: a MRI and SPECT study. Arq Neuropsiquiatr 2003;61:957-61.

\section{http://dx.doi.org/10.1590/S0004-282X2003000600013}

5.Libbey JE, Sweeten TL, McMahon WM, Fujinami RS. Autistic disorder and viral infections. J Neurovirol 2005;11:1-10.

http://dx.doi.org/10.1080/13550280590900553

6.Klin A, Mercadante MT. [Autism and the pervasive developmental disorders]. Rev Bras Psiquiatr 2006;28(Suppl 1):S1-2.

http://dx.doi.org/10.1590/S1516-44462006000500001

http://dx.doi.org/10.1590/S1516-44462006000500002

7.Classificação dos transtornos mentais e do comportamento da CID-10 [endereço na Internet]. Porto Alegre: Artes Médicas. (atualizado em agosto/2011; citado em: agosto/2011). Disponível em: http://www.datasus.gov.br/cid10/v2008/ cid10.htm.

8.Fombonne E. Epidemiology of autistic disorder and other pervasive developmental disorders. J Clin Psychiatry2005;66 (Suppl 10):3-8.

9.Fombonne E. Epidemiology of pervasive developmental disorders. Pediatr Res 2009;65:591-8.

http://dx.doi.org/10.1203/PDR.0b013e31819e7203

10.Theoharides TC, Kempuraj D, Redwood L. Autism: an emerging 'neuroimmune disorder' in search of therapy. Expert Opin Pharmacother 2009; 10:2127-43.

http://dx.doi.org/10.1517/14656560903107789

11.Wing L. Wing autistic disorder interview checklist (WADIC). In: Rapin I, editor. Preschool children with inadequate communication Developmental language disorder, autism, low IQ. London: Mac Keith Press, 1996, p.247-51. 12.Ajuriahuerra J. Las Psicosis Infantiles. Manual de Psiquiatria Infantil. Barcelona: Toray-Masson; 1977, p.673-731.

13.Kanner L. Autistic disturbances of affective contact. The nervous child $1943 ; 2: 217-50$.

14.Eisenberg L, Kanner L. Childhood schizophrenia; symposium, 1955. VI. Early infantile autism, 1943-55. Am J Orthopsychiatry 1956;26:556-66.

http://dx.doi.org/10.1111/j.1939-0025.1956.tb06202.x

15.Klein M. On early infantile psychosis: the symbiotic and autistic syndromes. J Am Acad Child Psychiatry 1965;4:554-68.

http://dx.doi.org/10.1016/S0002-7138(09)62158-0

16.Klein M. Os progressos da psicanálise (Original publicado em 1932). Rio de Janeiro: Zahar, 1989, p.79-135.

17.Mahler MD. On human symbiosis and the vicissitudes of individuation: Infantile psychosis. New York: International Universities; 1968, 271p.

18.Tustin F. Autistic states in children. London: Routledge and Kegan Paul; 1981, 272p.

19. Hobson P. Autism and the development of mind. Lawrence Erlbaum; 1993, $246 \mathrm{p}$.

20.Baron-Cohen S. Theory of mind and autism: A fifteen year review. In: Baron-Cohen S, Tager-Flusberg H, Cohen DJ, editors. Understanding other minds: Perspectives from developmental cognitive neuroscience. London: Oxford University Press, 2000, p.3-20.

21.Assumpção JFB, Kuczynski E, Sprovieri MH, Farinha V. Reconhecimento facial e autismo. Arq Neuropsiquiatr 1999;57:944-9.

http://dx.doi.org/10.1590/S0004-282X1999000600008

22.Hermelin B, O'Connor N. Psychological experiments with autistic children. New York: New York, 1970, 142p.
23. Bosa C, Callias M. Autismo: breve revisão de diferentes abordagens. Psicol Reflex Crit 2000;13:167-77.

http://dx.doi.org/10.1590/S0102-79722000000100017

24.O'Hare A. Autism spectrum disorder: diagnosis and management. Arch Dis Child Educ Pract Ed 2009;94:161-8.

http://dx.doi.org/10.1136/adc.2008.150490

25.Schopler E, Reichler RJ, DeVellis RF, Daly K. Toward objective classification of childhood autism: Childhood Autism Rating Scale (CARS). J Autism Dev Disord 1980;10:91-103.

http://dx.doi.org/10.1007/BF02408436

26.Krug DA, Arick J, Almond P. Behavior checklist for identifying severely handicapped individuals with high levels of autistic behavior. J Child Psychol Psychiatry 1980;21:221-9.

http://dx.doi.org/10.1111/j.1469-7610.1980.tb01797.x

27.Ashwood P, Wills S, Van de Water J. The immune response in autism: a new frontier for autism research. J Leukoc Biol 2006;80:1-15.

http://dx.doi.org/10.1189/jlb.1205707

28.Bauman M, Kemper TL. Histoanatomic observations of the brain in early infantile autism. Neurology 1985;35:866-74.

29. Courchesne E, Yeung-Courchesne R, Press GA, Hesselink JR, Jernigan TL. Hypoplasia of cerebellar vermal lobules VI and VII in autism. N Engl J Med 1988;318:1349-54.

http://dx.doi.org/10.1056/NEJM198805263182102

30.Murakami JW, Courchesne E, Press GA, Yeung-Courchesne R, Hesselink JR. Reduced cerebellar hemisphere size and its relationship to vermal hypoplasia in autism. Arch Neurol 1989;46:689-94.

31.Allen G, Courchesne E. Differential effects of developmental cerebellar abnormality on cognitive and motor functions in the cerebellum: an fMRI study of autism. Am J Psychiatry 2003;160:262-73.

http://dx.doi.org/10.1176/appi.ajp.160.2.262

32.Gadia CA, Tuchman R, Rotta NT. Autism and pervasive developmental disorders. J Pediatr (Rio J) 2004;80:S83-94.

http://dx.doi.org/10.2223/JPED.1172

http://dx.doi.org/10.2223/1172

33.Pardo CA, Vargas DL, Zimmerman AW. Immunity, neuroglia and neuroinflammation in autism. Int Rev Psychiatry 2005;17:485-95.

http://dx.doi.org/10.1080/02646830500381930

34.Salgado-Pineda P, Delaveau P, Blin O, Nieoullon A. Dopaminergic contribution to the regulation of emotional perception. Clin Neuropharmacol 2005;28:228-37.

http://dx.doi.org/10.1097/01.wnf.0000185824.57690.f0

35.Cook EH, Jr. Genetics of autism. Child Adolesc Psychiatr Clin N Am 2001;10:333-50.

36.Risch N, Spiker D, Lotspeich L, Nouri N, Hinds D, Hallmayer J, et al. A genomic screen of autism: evidence for a multilocus etiology. Am J Hum Genet 1999;65:493-507.

http://dx.doi.org/10.1086/302497

37.Cook EH, Jr., Courchesne R, Lord C, Cox NJ, Yan S, Lincoln A, et al. Evidence of linkage between the serotonin transporter and autistic disorder. Mol Psychiatry 1997;2:247-50.

http://dx.doi.org/10.1038/sj.mp.4000266

38.Rapin I, Katzman R. Neurobiology of autism. Ann Neurol 1998;43:7-14. http://dx.doi.org/10.1002/ana.410430106

39.Newschaffer CJ, Fallin D, Lee NL. Heritable and nonheritable risk factors for autism spectrum disorders. Epidemiol Rev 2002;24:137-53.

http://dx.doi.org/10.1093/epirev/mxf010

40.Cohen D, Pichard N, Tordjman S, Baumann C, Burglen L, Excoffier E, et al. Specific genetic disorders and autism: clinical contribution towards their 
identification. J Autism Dev Disord 2005;35:103-16.

http://dx.doi.org/10.1007/s10803-004-1038-2

41.Deverman BE, Patterson PH. Cytokines and CNS development. Neuron 2009;64:61-78.

http://dx.doi.org/10.1016/j.neuron.2009.09.002

42.Herbert MR. Contributions of the environment and environmentally vulnerable physiology to autism spectrum disorders. Curr Opin Neurol 2010;23:103-10

http://dx.doi.org/10.1097/WCO.0b013e328336a01f

43.Wing L, Potter D. The epidemiology of autistic spectrum disorders: is the prevalence rising? Ment Retard Dev Disabil Res Rev 2002;8:151-61.

http://dx.doi.org/10.1002/mrdd.10029

44.Larsson HJ, Eaton WW, Madsen KM, Vestergaard M, Olesen AV, Agerbo E, et al. Risk factors for autism: perinatal factors, parental psychiatric history, and socioeconomic status. Am J Epidemiol 2005;161:916-28.

http://dx.doi.org/10.1093/aje/kwi123

45.Bailey A, Luthert P, Dean A, Harding B, Janota I, Montgomery M, et al. A clinicopathological study of autism. Brain 1998;121(Pt 5):889-905.

http://dx.doi.org/10.1093/brain/121.5.889

46.Guerin P, Lyon G, Barthelemy C, Sostak E, Chevrollier V, Garreau B, et al. Neuropathological study of a case of autistic syndrome with severe mental retardation. Dev Med Child Neurol 1996;38:203-11.

http://dx.doi.org/10.1111/j.1469-8749.1996.tb15082.x

47.Warren RP, Margaretten NC, Pace NC, Foster A. Immune abnormalities in patients with autism. J Autism Dev Disord 1986;16:189-97.

http://dx.doi.org/10.1007/BF01531729

48.van Gent T, Heijnen CJ, Treffers PD. Autism and the immune system. J Child Psychol Psychiatry 1997;38:337-49.

http://dx.doi.org/10.1111/j.1469-7610.1997.tb01518.x

49.Dalton P, Deacon R, Blamire A, Pike M, McKinlay I, Stein J, et al. Maternal neuronal antibodies associated with autism and a language disorder. Ann Neurol 2003;53:533-7.

http://dx.doi.org/10.1002/ana.10557

50.Zimmerman AW. The immune system. In: Bauman M, Kemper TL, editors. The neurobiology of autism. Baltimore: The Johns Hopkins University Press; 2005, p.371-86.

51.Dantzer R, Kelley KW. Autistic children: a neuroimmune perspective. Brain Behav Immun 2008;22:804-5.

http://dx.doi.org/10.1016/j.bbi.2008.03.001

52.Stubbs EG, Crawford ML. Depressed lymphocyte responsiveness in autistic children. J Autism Child Schizophr 1977;7:49-55.

http://dx.doi.org/10.1007/BF01531114

53.Gupta S, Aggarwal S, Rashanravan B, Lee T. Th1- and Th2-like cytokines in CD4+ and CD8+ T cells in autism. J Neuroimmunol 1998;85:106-9.

http://dx.doi.org/10.1016/S0165-5728(98)00021-6

54.Singh VK, Warren R, Averett R, Ghaziuddin M. Circulating autoantibodies to neuronal and glial filament proteins in autism. Pediatr Neurol 1997;17:88-90. http://dx.doi.org/10.1016/S0887-8994(97)00045-3

55.Singh VK, Lin SX, Newell E, Nelson C. Abnormal measles-mumps-rubella antibodies and CNS autoimmunity in children with autism. J Biomed Sci 2002;9(4):359-64.

http://dx.doi.org/10.1007/BF02256592

56.Vojdani A, Campbell AW, Anyanwu E, Kashanian A, Bock K, Vojdani E. Antibodies to neuron-specific antigens in children with autism: possible crossreaction with encephalitogenic proteins from milk, Chlamydia pneumoniae and Streptococcus group A. J Neuroimmunol 2002;129(1-2):168-77.

http://dx.doi.org/10.1016/S0165-5728(02)00180-7

57.Jyonouchi H, Sun S, Le H. Proinflammatory and regulatory cytokine pro- duction associated with innate and adaptive immune responses in children with autism spectrum disorders and developmental regression. J Neuroimmunol 2001;120(1-2):170-9.

http://dx.doi.org/10.1016/S0165-5728(01)00421-0

58. Chess S, Fernandez P, Korn S. Behavioral consequences of congenital rubella. J Pediatr 1978;93:699-703.

http://dx.doi.org/10.1016/S0022-3476(78)80921-4

59.Yamashita Y, Fujimoto C, Nakajima E, Isagai T, Matsuishi T. Possible association between congenital cytomegalovirus infection and autistic disorder. J Autism Dev Disord 2003;33:455-9.

http://dx.doi.org/10.1023/A:1025023131029

60.Rosenberger PB. Editorial: Infectious disease and the immature brain. N Engl J Med 1975;293:39-40.

http://dx.doi.org/10.1056/NEJM197507032930110

61.Sells CJ, Carpenter RL, Ray CG. Sequelae of central-nervous-system enterovirus infections. N Engl J Med 1975;293:1-4.

http://dx.doi.org/10.1056/NEJM197507032930101

62. Weinberg ED. Pregnancy-associated depression of cell-mediated immunity. Reviews of Infectious Diseases 1984;6:814-31.

http://dx.doi.org/10.1093/clinids/6.6.814

63.Sargent IL. Maternal and fetal immune responses during pregnancy. Exp Clin Immunogenet 1993;10:85-102.

64.Munoz-Fernandez MA, Fresno M. The role of tumour necrosis factor, interleukin 6, interferon-gamma and inducible nitric oxide synthase in the development and pathology of the nervous system. Progress in Neurobiology 1998;56:307-40.

http://dx.doi.org/10.1016/S0301-0082(98)00045-8

65.Chez MG, Dowling T, Patel PB, Khanna P, Kominsky M. Elevation of tumor necrosis factor-alpha in cerebrospinal fluid of autistic children. Pediatr Neurol 2007;36:361-5.

http://dx.doi.org/10.1016/j.pediatrneurol.2007.01.012

66.Sweeten TL, Posey DJ, McDougle CJ. High blood monocyte counts and neopterin levels in children with autistic disorder. Am J Psychiatry 2003;160:1691-3.

http://dx.doi.org/10.1176/appi.ajp.160.9.1691

67.Vargas DL, Nascimbene C, Krishnan C, Zimmerman AW, Pardo CA. Neuroglial activation and neuroinflammation in the brain of patients with autism. Ann Neurol 2005;57:67-81.

http://dx.doi.org/10.1002/ana.20315

68.Jansen LM, Gispen-de Wied CC, van der Gaag RJ, van Engeland H. Differentiation between autism and multiple complex developmental disorder in response to psychosocial stress. Neuropsychopharmacology 2003;28:582-90.

http://dx.doi.org/10.1038/sj.npp.1300046

69.Tani P, Lindberg N, Matto V, Appelberg B, Nieminen-von Wendt T, von Wendt L, et al. Higher plasma ACTH levels in adults with Asperger syndrome. J Psychosom Res 2005;58:533-6.

http://dx.doi.org/10.1016/j.jpsychores.2004.12.004

70.Boksa P. Effects of prenatal infection on brain development and behavior: A review of findings from animal models. Brain Behav Immun 2010; [in press]. http://dx.doi.org/10.1016/j.bbi.2010.03.005

71.Patterson PH. Maternal infection: window on neuroimmune interactions in fetal brain development and mental illness. Curr Opin Neurobiol 2002;12:115-8.

http://dx.doi.org/10.1016/S0959-4388(02)00299-4

72.Meyer U, Yee BK, Feldon J. The neurodevelopmental impact of prenatal infections at different times of pregnancy: the earlier the worse? Neuroscientist 2007;13:241-56.

http://dx.doi.org/10.1177/1073858406296401 
73.Smith SEP, Li J, Garbett K, Mirnics K, Patterson PH. Maternal immune activation alters fetal brain development through interleukin-6. J Neurosci 2007;27:10695-702.

http://dx.doi.org/10.1523/JNEUROSCI.2178-07.2007

74.Fortier ME, Luheshi GN, Boksa P. Effects of prenatal infection on prepulse inhibition in the rat depend on the nature of the infectious agent and the stage of pregnancy. Behav Brain Res 2007;181:270-7.

http://dx.doi.org/10.1016/j.bbr.2007.04.016

75.Moy SS, Nadler JJ, Poe MD, Nonneman RJ, Young NB, Koller BH, et al. Development of a mouse test for repetitive, restricted behaviors: relevance to autism. Behav Brain Res 2008;188:178-94.

http://dx.doi.org/10.1016/j.bbr.2007.10.029

76.Pletnikov MV, Rubin SA, Vasudevan K, Moran TH, Carbone KM. Developmental brain injury associated with abnormal play behavior in neonatally Borna disease virus-infected Lewis rats: a model of autism. Behav Brain Res 1999; 100(1-2):43-50.

http://dx.doi.org/10.1016/S0166-4328(98)00111-9
77.Hornig M, Weissenbock H, Horscroft N, Lipkin WI. An infection-based model of neurodevelopmental damage. Proc Natl Acad Sci U S A 1999;96:12102-7. http://dx.doi.org/10.1073/pnas.96.21.12102

78.Shi L, Fatemi SH, Sidwell RW, Patterson PH. Maternal influenza infection causes marked behavioral and pharmacological changes in the offspring. J Neurosci 2003;23:297-302.

79.Kirsten TB, Taricano M, Maiorka PC, Palermo-Neto J, Bernardi MM. Prenatal lipopolysaccharide reduces social behavior in male offspring. Neuroimmunomodulation 2010;17:240-51.

http://dx.doi.org/10.1159/000290040

80Taricano M. Efeitos da administraçáo pré-natal de LPS no aprendizado e/ ou memória na prole de ratas (dissertação). São Paulo: Instituto de Psicologia, Universidade de São Paulo; 2010, 104p.

81.Ingram JL, Peckham SM, Tisdale B, Rodier PM. Prenatal exposure of rats to valproic acid reproduces the cerebellar anomalies associated with autism. Neurotoxicol Teratol 2000;22:319-24.

http://dx.doi.org/10.1016/S0892-0362(99)00083-5 